\title{
Formulation, application and evaluation of a stack emission model for coal-based power stations
}

\author{
P. P. Walvekar · B. R. Gurjar
}

Received: 19 February 2012/Revised: 25 May 2012/Accepted: 2 August 2012/Published online: 27 November 2012

(c) CEERS, IAU 2012

\begin{abstract}
Estimation of coal power plant emissions is a vital step to visualise emission trends with respect to specific policy implementations and technological interventions so that their effectiveness in terms of emission reductions and ambient air quality improvement can be quantitatively assessed. However, research work concerning stack emission estimations specifically for coal power plants in India is limited. To bridge the present gap, we present a plant-specific multi-year and multi-parameter Coal Power Stack Emission Model. This model has been developed to explore current and historical annual stack emissions from a coal-based thermal power plant taking into account essential variables such as coal characteristics, process attributes and control equipment aspects, which can significantly influence the stack emissions. This study concentrates on development of Coal Power Stack Emission model and its application for the estimation of plant and year-specific emission factors and stack emissions for a coal-based power plant at Badarpur, New Delhi, for the period of 2000-2008. The validation of Coal Power Stack Emission model has also been successfully carried out by comparing the trends of percentage change in annual emission estimates and observed ambient air concentrations of total suspended particles, $\mathrm{PM}_{10}$ and sulphur dioxide at two nearby air quality monitoring stations, namely Siri Fort and Nizamuddin.
\end{abstract}

\footnotetext{
P. P. Walvekar · B. R. Gurjar $(\square)$

Department of Civil Engineering,

Indian Institute of Technology,

Roorkee, India

e-mail: brgurjar@gmail.com; bholafce@iitr.ernet.in

P. P. Walvekar

e-mail: walvekarpralhad@gmail.com
}

Keywords Emission control - Emission factor . Emission inventory $\cdot$ Power plant technology

\section{Introduction}

Air quality concern has been one of the prime environmental issues for the Indian government and public alike for past few decades. The Ministry of Environment and Forests (MoEF), Government of India, has been taking appropriate policy decisions so as to reduce near- and longterm air pollution emissions and consequences. Power sector is a major contributor to air pollution emissions, particularly that of particulate matter (PM) and sulphur dioxide $\left(\mathrm{SO}_{2}\right)$. According to MoP (Ministry of Power) (2011) the all India installed power generation capacity as on December 31, 2010 was about 169749 MW comprising of $\sim 111034 \mathrm{MW}$ thermal $(\sim 65 \%), \sim 36367 \mathrm{MW}$ hydro (22\%), $4560 \mathrm{MW}$ nuclear $(\sim 3 \%)$ and $\sim 16787 \mathrm{MW}$ renewable $(\sim 10 \%)$, which clearly indicates the dominance of thermal power. Coal is expected to dominate the thermal power sector consumption (presently $83 \%$ share) at least for the next three decades in India. The major reason for the dominance of coal power is the cost effectiveness of fuel than other alternative fuels like natural gas, hydropower and nuclear (Asian Development Bank (ADB) 2009).

There are several studies on estimation of emissions from different sources, but emission inventories specifically related to coal power plants in India are sparse and limited to specific pollutants. For example, Shrestha and Timilsina (1997) have estimated $\mathrm{SO}_{2}$ emission intensities of the power sector based on fuel analysis in 12 selected Asian economies during the period 1980-1994 including India. Reddy and Venkataraman (2002) constructed 
for the first time a comprehensive, spatially resolved $\left(0.25^{\circ} \times 0.25^{\circ}\right)$ fossil fuel consumption database and emission inventory for fossil fuel consumption in India. In this inventory, emissions of sulphur dioxide and aerosol chemical constituents were estimated for 1996-1997. Mittal and Sharma (2004), on the other hand, used stoichiometric analysis for developing emission inventories for thermal power plants in India. Raghuvanshi et al. (2006) prepared an inventory of $\mathrm{CO}_{2}$ emissions in 2004 from the present energy generation and predicted the same for the next two decades (until 2025). Garg et al. (2006) provided multigas emission inventory of GHGs and air pollutants in India from various sources for the period of 1985-2005. Chakraborty et al. (2008) presented for the very first time emissions from thermal power plants only, which were based on online measurements carried out in a plant following the standard experimental guidelines. Ghosh (2010) aimed to analyse thermal power generation in India for the period 2004-2005 and 2007-2008 to determine net generation and specific $\mathrm{CO}_{2}$ emissions. It has been observed that most of the studies do not include technological changes and fuel characteristics, which can greatly influence the emission estimations. Few studies have estimated stack emissions considering only selected variables and the combined effect of all concerned variables on these emissions was left untouched. Since most of the emission estimation studies in India are limited to few pollutants or greenhouse gases only, this may not provide a clear and comprehensive picture of emissions for policy making purpose. Power plant emissions have been the target for investigating the pollutant dispersion pattern using various types of air dispersion models (Kho et al., 2007; Awasthi et al., 2006). The emission model that can estimate power plant emissions could be useful as a first step in air quality modelling. But there is no such model available for stack emission estimation from coal power plants in India.

In the present study, a simple stack emission model, namely the "Coal Power Stack Emission (CPSE)" model has been developed to estimate and explore current and historical emission trends of important pollutants and GHGs like total suspended particles (TSP), $\mathrm{PM}_{10}, \mathrm{PM}_{2.5}, \mathrm{SO}_{2}$, $\mathrm{NO}_{\mathrm{x}}, \mathrm{CO}_{2}$ and $\mathrm{Hg}$ from a coal power plant. The emission estimation methodology takes into account essential variables like coal characteristics (e.g. ash content, sulphur content, mercury content, indigenous/imported coal), technological attributes (e.g. plant technology, type of turbine, sub/super critical process) and control equipment features (e.g. availability of desulphurisation, low NOx burners, catalytic reactors, Electro-Static Precipitator, bag house, age of ESP, up-gradation of ESP if any). The proposed CPSE model has been used to establish emissions from a coal-based power plant at Badarpur, New Delhi during 2000-2008. The comparison between percentage change in annual emissions and observed ambient air concentrations at nearby air quality monitoring stations has been carried out for successful validation of CPSE model.

\section{Materials and methods}

Plant-specific methodology

The plant-specific multi-year, multi-parameter CPSE model is developed using MS Excel and Visual Basic Application (VBA) to estimate current and historical annual emissions from a coal-based power plant taking into account essential variables which can be of great effect on emission levels. The CPSE model estimates annual stack emissions of particulates (e.g. TSP, $\mathrm{PM}_{10}, \mathrm{PM}_{2.5}$ ), gaseous pollutants (e.g. $\mathrm{NO}_{\mathrm{x}}, \mathrm{SO}_{2}$ ), greenhouse gases (GHGs) (e.g. $\mathrm{CO}_{2}$ ) and hazardous pollutants (e.g. $\mathrm{Hg}$ ) for several years simultaneously using emission factor or fuel consumption approach. We have used fuel analysis approach instead of emission factors to estimate emissions of TSP, $\mathrm{PM}_{10}$, $\mathrm{PM}_{2.5}, \mathrm{SO}_{2}$ and $\mathrm{Hg}$. This has been carried out in such a way that readily and reliably available local data and correction factors are used to estimate the emissions using Eqs. (1) (3) and (5), respectively. The emission factor-based approach has been used to estimate emissions of $\mathrm{CO}_{2}$ and $\mathrm{NO}_{\mathrm{x}}$ using Eqs. (2) and (4), respectively.

$$
\begin{aligned}
& E_{\mathrm{PM}_{Y}}=(\mathrm{CC} \times A)_{y} \times\left(1-A_{\mathrm{r}}\right) \times\left(1-\eta_{g, h, j, n}\right) \times D \times K \\
& E_{\mathrm{NO}_{x}}=\mathrm{CC} \times \mathrm{EF}_{\mathrm{NO}_{x}, b, g} \times D \\
& E_{\mathrm{SO}_{2}}=\mathrm{CC} \times S \times \frac{\mathrm{MW}_{p}}{\mathrm{MW}_{f}} \times\left(1-S_{\mathrm{r}}\right) \times\left(1-\eta_{g}\right) \\
& E_{\mathrm{CO}_{2}}=G \times \mathrm{EF}_{\mathrm{CO}_{2}, f, c c s} \\
& E_{H_{g}}=\mathrm{CC} \times H_{g} \times L \times\left(1-\eta_{g, h, j}\right) \times D
\end{aligned}
$$

where subscripts $b, f, g, h, j, n$, ccs and y stand for boiler type, process, emission control technology, age of electrostatic precipitator (ESP), up-gradation of ESP, low sulphurcontent factor, availability of carbon capture and storage (CCS) facility and particulate size. Furthermore, $\mathrm{CC}$ is total coal consumption (kt), $A$ is ash content in coal (\%), $A_{\mathrm{r}}$ is fraction of ash retained, $\eta$ is control efficiency (\%), $D$ is plant technology factor, $K$ is particulate fraction by size, EF is emission factor $(\mathrm{t} / \mathrm{kt}), S$ is fraction of sulphur content in coal, $S_{\mathrm{r}}$ is sulphur retained, $\mathrm{MW}_{\mathrm{p}}$ is molecular weight of pollutant $(\mathrm{g} / \mathrm{mol}), \mathrm{MW}_{\mathrm{f}}$ is molecular weight of fuel $(\mathrm{g} / \mathrm{mol})$, $\mathrm{G}$ is gross generation $(\mathrm{GWh}), H_{\mathrm{g}}$ is mercury content in coal $(\mathrm{t} / \mathrm{kt})$ and $L$ is fraction release rate of mercury. 
Activity

The total coal consumption $(C C)$ was computed by adding indigenous, washed and imported coal consumed in the plant as shown in Eq. (6):

$\mathrm{CC}=\mathrm{CC}_{\mathrm{i}}+\mathrm{CC}_{\mathrm{w}}+\mathrm{CC}_{\mathrm{m}}$

where $\mathrm{CC}_{\mathrm{i}}, \mathrm{CC}_{\mathrm{w}}$ and $\mathrm{CC}_{\mathrm{m}}$ stand for indigenous, washed and imported coal consumed in the plant, respectively.

In case of lack of availability of coal consumption data according to coal type, total coal consumption was calculated based on gross generation and specific coal consumption in the plant suggested by Gurjar et al. (2004). These equations for calculating gross generation $(G)$ and total coal consumption (CC) are given here as Eqs. (7) and (8):

$G=C \times \mathrm{PLF} \times 24 \times 365$

$\mathrm{CC}=G \times \mathrm{SPCC}$

where $\mathrm{C}$ is derated capacity of power plant (GW), PLF is plant load factor (\%) and SPCC is specific coal consumption (kt/GWh).

The total ash $(\mathrm{CC} \times A)$, sulphur $(\mathrm{CC} \times S)$ and mercury contents $\left(\mathrm{CC} \times H_{\mathrm{g}}\right)$ in coal were calculated by adding the products of consumption of coal (indigenous, washed and imported) and ash, sulphur and mercury content of respective type of coal as shown in Eqs (9-11).

$(\mathrm{CC} \times A)=\left(\mathrm{CC}_{\mathrm{i}} \times A_{\mathrm{i}}\right)+\left(\mathrm{CC}_{\mathrm{w}} \times A_{\mathrm{W}}\right)+\left(\mathrm{CC}_{\mathrm{m}} \times A_{\mathrm{m}}\right)$

$\mathrm{CC} \times S=\left(\mathrm{CC}_{\mathrm{i}} \times S_{\mathrm{i}}\right)+\left(\mathrm{CC}_{\mathrm{w}} \times S_{\mathrm{w}}\right)+\left(\mathrm{CC}_{\mathrm{m}} \times S_{\mathrm{m}}\right)$

$\mathrm{CC} \times H_{\mathrm{g}}=\left(\mathrm{CC}_{\mathrm{i}} \times H_{\mathrm{g}_{\mathrm{i}}}\right)+\left(C C_{\mathrm{w}} \times H_{\mathrm{g}_{\mathrm{w}}}\right)+\left(\mathrm{CC}_{\mathrm{m}} \times H_{\mathrm{g}_{\mathrm{m}}}\right)$

where $\left(\mathrm{CC}_{\mathrm{i}} \times A_{\mathrm{i}}\right)$ is total indigenous coal ash content (\%), $\left(\mathrm{CC}_{\mathrm{w}} \times A_{\mathrm{w}}\right)$ is total washed coal ash content $(\%),\left(\mathrm{CC}_{\mathrm{m}} \times\right.$ $\left.A_{\mathrm{m}}\right)$ is total imported coal ash content $(\%),\left(\mathrm{CC}_{\mathrm{i}} \times S_{\mathrm{i}}\right)$ is total indigenous coal fraction sulphur content, $\left(\mathrm{CC}_{\mathrm{w}} \times S_{\mathrm{w}}\right)$ is total washed coal fraction sulphur content, $\left(\mathrm{CC}_{\mathrm{m}} \times\right.$ $\left.S_{\mathrm{m}}\right)$ is total imported coal fraction sulphur content, $\left(\mathrm{CC}_{\mathrm{i}} \times H_{\mathrm{gi}}\right)$ is total indigenous coal mercury content $(t),\left(\mathrm{CC}_{\mathrm{w}} \times H_{\mathrm{gw}}\right)$ is total washed coal mercury content $(t)$ and $\left(\mathrm{CC}_{\mathrm{m}} \times H_{\mathrm{gm}}\right)$ is total imported coal mercury content $(t)$.

Essential variables and basic emission rates

As discussed below, many researchers have studied the effects of various variables such as coal characteristics, technological attributes and control equipment aspects on coal power plant efficiency and resulting emissions.

\section{Coal characteristics}

As far as coal characteristics are considered, it is well known that less ash, sulphur and mercury content in coal leads to lesser amount of stack emissions of particulates, $\mathrm{SO}_{2}$ and $\mathrm{Hg}$, respectively. Also, percentage of ash and sulphur retained, fraction release rate of mercury and type of coal consumed (indigenous, washed or imported) are the key factors influencing their stack emissions. The CPSE model provides flexibility in selecting types of coal as indigenous, washed and imported separately and also combinations therein. The user has to fill in ash, sulphur and mercury content of coal as per type of coal burnt in the plant.

\section{Process attributes}

There are several process attributes of coal power plant that, too, influence stack emissions of various parameters, one of them being the type of the boiler, such as tangentially fired or swirl burner. The emission factor of $\mathrm{NO}_{\mathrm{x}}$ emissions for normal firing is normally much higher as compared with tangentially fired boilers (Vijay et al., 2004). Accordingly, CPSE model uses $\mathrm{NO}_{\mathrm{x}}$ emission factor based on selection between two types of boilers, namely tangentially fired and swirl burner which significantly influence the $\mathrm{NO}_{\mathrm{x}}$ emissions from a coal power plant.

The plant technology also plays a key role in stack emissions of various pollutants. According to Ghosh (2011), if advanced technology like integrated gasification of combined cycle (IGCC) is used instead of Pulverized coal (PC) in coal power plants, then stack emission of particulate, $\mathrm{NO}_{\mathrm{x}}$ and $\mathrm{SO}_{2}$ are reduced by about 7, 20 and $16 \%$, respectively. Plant technology influences also the particulate fraction by size. The particulate size fraction for the said plant technology is adapted from Zhao et al. (2008) so as to estimate $\mathrm{PM}_{2.5}$ and $\mathrm{PM}_{10}$ emissions. Furthermore, a study by Tian et al. (2010) reveals that the release rate of $\mathrm{Hg}$ stack emissions is more than $99 \%$ provided the PC technology is used in coal power plant. Consequently, Grate, PC and IGCC are the options for coal power plant technology that are made available to users in the proposed CPSE model.

The type of the process technology (e.g. sub-critical, super-critical, ultra-supercritical or IGCC) used in a coal power plant also significantly affects $\mathrm{CO}_{2}$ emissions. According to Rezvani et al. (2007), for example, the specific $\mathrm{CO}_{2}$ emission for the super-critical plant is $12 \%$ lower than the one for the sub-critical system. Beer (2007) specifies $\mathrm{CO}_{2}$ emissions in $\mathrm{kg} / \mathrm{KWh}$ for all these process technologies with and without carbon capture and storage (CCS). The CPSE model provides all these four alternatives with and without CCS to user for the selection of process technology. 


\section{Stack emission control equipment aspects}

The advanced technologies in terms of emission controlling equipments (e.g. ESPs) can be used to control stack emissions of flue gases from coal power plants. Similar to the UK and the EU, in India ESPs and fabric filters are the recommended technologies (Soltanali et al., 2008) for removing particulates and heavy metals. In case of particulate control, filter bag house performs at $99 \%$ efficiency continually, whereas performance of ESP declines over the years if not maintained regularly. Sengupta (2007) has observed that the rate at which design efficiency of ESP declines is $1 \%$ per year. Also, the low sulphur content of coal turns down dust removal efficiency of ESP significantly. According to Wang et al. (2001), reduction in dust removal efficiency was found to be $2.47 \%$ when sulphur content in coal was lowered from 1.25 to $0.65 \%$. Based on these results, the CPSE model takes into account either ESP or filter bag house as two alternatives for particulate control equipment along with installation, up-gradation year and design efficiency of ESP. The CPSE model also reflects the effect of low sulphur content in coal on ESP if it has been used in a coal power plant.

Generally, Low $\mathrm{NO}_{\mathrm{x}}$ Burners (LNBs), selective catalytic reduction (SCR) and selective non-catalytic reduction (SNCR) are used for $\mathrm{NO}_{\mathrm{x}}$ emission control as needed based on existing power plant technology (Chikkatur and Sagar, 2007). It has been observed that SCR system can reduce $70-90 \%$ while SNCR system can remove $30-70 \%$ of $\mathrm{NO}_{\mathrm{x}}$ emissions from coal power plants. Accordingly, the CPSE model uses $\mathrm{NO}_{\mathrm{x}}$ emission factor based on various control options as no control, LNB, SCR, SNCR, combined LNB and SCR as well as combined LNB and SNCR.

Significant reduction in $\mathrm{SO}_{2}$ emissions was observed due to wide application of the flue gas desulphurization (FGD) technology in China (Zhao et al. 2008). Miller et al. (2006) stated that dry FGD systems can attain 90-95\% $\mathrm{SO}_{2}$ emission control and are typically used at plants burning low-sulphur coal, whereas wet FGD systems can attain $95-98 \% \mathrm{SO}_{2}$ emission control and are typically used at plants burning high-sulphur coal. Therefore, to incorporate $\mathrm{SO}_{2}$ control mechanism three options are offered in CPSE model, which are (1) no control available, (2) dry FGD and (3) wet FGD.

It is worth noting that the control equipments used for particulate and $\mathrm{SO}_{2}$ abatements also remove $\mathrm{Hg}$ emissions to a certain extent as a co-benefit. According to Tian et al. (2010), control equipments like ESP, FF and FGD are also responsible for the removal of $\mathrm{Hg}$ emissions by about 33, 68 and $57 \%$. These co-benefits are also taken into account in the CPSE model for estimating $\mathrm{Hg}$ stack emissions.
Table 1 Basic emission rate for $\mathrm{CO}_{2}$ used in CPSE Model $(\mathrm{kt} / \mathrm{GWh})$

\begin{tabular}{lll}
\hline Process technology & \multicolumn{2}{l}{ CCS } \\
\cline { 2 - 3 } & Yes & No \\
\hline Sub-critical & 127 & 913 \\
Super-critical & 109 & 830 \\
Ultra-supercritical & 94 & 738 \\
IGCC & 101 & 824 \\
\hline
\end{tabular}

\section{Basic emission rates}

Unfortunately, there is no field study that gives $\mathrm{CO}_{2}$ and $\mathrm{NO}_{\mathrm{x}}$ emission factors for Indian coal power plants considering effects of important aspects like plant technology, process attributes and control equipments. However, Beer (2007) and Zhao et al. (2008) have provided emission rates of $\mathrm{CO}_{2}$ and $\mathrm{NO}_{\mathrm{x}}$, respectively, based on these important aspects. Accordingly, in CPSE model, the estimation of $\mathrm{CO}_{2}$ stack emissions is based on emission rates given by Beer (2007) for various process technologies used in coal power plants with and without CCS while the estimation of $\mathrm{NO}_{\mathrm{x}}$ emissions is based on emission factors given by Zhao et al. (2008) according to boiler type and control equipments used. Table 1 and 2 give basic emission rates for $\mathrm{CO}_{2}$ and $\mathrm{NO}_{\mathrm{x}}$ used in the proposed CPSE model.

\section{Results and discussion}

In the present study, stack emissions have been estimated using the proposed CPSE model for Badarpur Thermal Power Station (BTPS), New Delhi, from 2000 to 2008. The user form of CPSE model giving the information about requirement of various input variables of a coal power plant is shown in Fig. 1.

The input data required for stack emission estimation were obtained from various publications like performance review reports published by Central Electricity Authority (CEA), CBIP (Central Board of Irrigation and Power) (1997) and TERI (The Energy and Resources Institute) (2011). The characteristics of BTPS, New Delhi, which were taken into consideration for stack emission estimation are listed in Table 3.

\section{Particulate emissions}

The particulate stack emissions and coal consumption in BTPS, New Delhi, during 2000-2008 are illustrated in Fig. 2a for TSP and $\mathrm{PM}_{10}$, and in Fig. $2 b$ for $\mathrm{PM}_{2.5}$.

During 2000-2004, emissions of TSP, $\mathrm{PM}_{10}$ and $\mathrm{PM}_{2.5}$ were initially high enough to reach to around 32,25 and $1.6 \mathrm{kt}$, respectively. However, in 2004 due to the up- 
Table 2 Basic emission rate for $\mathrm{NO}_{\mathrm{x}}$ used in CPSE Model (t/kt)

\begin{tabular}{lllllll}
\hline $\begin{array}{l}\text { Type of } \\
\text { boiler }\end{array}$ & $\begin{array}{l}\text { No } \\
\text { control }\end{array}$ & $\begin{array}{l}\text { Low } \\
\mathrm{NO}_{\mathrm{x}} \\
\text { burner }\end{array}$ & $\begin{array}{l}\text { Selective } \\
\text { catalytic } \\
\text { reduction }\end{array}$ & $\begin{array}{l}\text { Low } \mathrm{NO}_{\mathrm{x}} \text { burner } \\
\text { and selective } \\
\text { catalytic reduction }\end{array}$ & $\begin{array}{l}\text { Non- } \\
\text { selective } \\
\text { catalytic } \\
\text { reduction }\end{array}$ & $\begin{array}{l}\text { Low } \mathrm{NO}_{\mathrm{x}} \text { burner } \\
\text { and Non-selective } \\
\text { catalytic reduction }\end{array}$ \\
\hline Tangentially fired & 6.6 & 4.05 & 1.32 & 0.81 & 3.3 & 2.03 \\
Swirl burner & 7.4 & 5.46 & 1.48 & 1.09 & 3.7 & 2.73 \\
\hline
\end{tabular}

Fig. 1 User form of CPSE Model



Table 3 Characteristics of Badarpur Thermal Power Station, New Delhi (CBIP (Central Board of Irrigation and Power) 1997; TERI (The Energy and Resources Institute) 2011)

\begin{tabular}{ll}
\hline & Characteristics \\
\hline Derated capacity (MW) & 705 \\
Plant technology & Pulverized coal \\
Type of boiler & Tangentially fired \\
Process technology & Sub-critical \\
Desulphurization & No \\
NO $_{x}$ control technology & Low $\mathrm{NO}_{\mathrm{x}}$ burner \\
Particulate control equipment & Electro static precipitator \\
Year of ESP Installation & 1978 \\
year of ESP up-gradation & 2004 \\
Design efficiency of ESP $(\%)$ & 99.61 \\
\hline
\end{tabular}

gradation of ESPs there was sudden decrease of about $90 \%$ in all types of particulate emissions from stacks. Later on, particulate emissions in 2008 increased to about 2.5 times compared with those of 2005. It is observed that increasing trends of all types of particulate stack emissions from 2005 to 2008 were not similar or equivalent to trend of coal consumption. A possible reason for this could be the declining efficiency of electrostatic precipitator over the years (Sengupta, 2007).
Gaseous pollutants emissions

The emission of gaseous pollutants $\left(\mathrm{SO}_{2}, \mathrm{NO}_{\mathrm{x}}\right)$ and coal consumption in BTPS, New Delhi, during 2000-2008 are illustrated in Fig. 3. Stack emissions of both $\mathrm{SO}_{2}$ and $\mathrm{NO}_{\mathrm{x}}$ increased from 2000 to 2001 by $10 \%$ and later on decreased by about $6 \%$ between 2001 and 2003. Since then it increased gradually up to 2006, subsequent to the trend of coal consumption in power plant. There was sudden rise (12\%) in $\mathrm{NO}_{\mathrm{x}}$ and $\mathrm{SO}_{2}$ emissions in 2007 because of rapid increase in fuel consumption which gradually increased thereafter. An increase of about $24 \%$ was observed in both $\mathrm{SO}_{2}$ and $\mathrm{NO}_{\mathrm{x}}$ emissions from 2003 to 2008 as no control measures for $\mathrm{SO}_{2}$ emissions had been used during that period in the plant. As far as $\mathrm{NO}_{\mathrm{x}}$ emission control is considered, LNB had been implemented in the plant. In spite of availability of LNB in the plant for $\mathrm{NO}_{\mathrm{x}}$ control, the rapid growing trend of $\mathrm{NO}_{\mathrm{x}}$ emissions during 2003 to 2008 implies that the emission control effect of LNB was quite poor and requires implementation of improved control policy. Also, it is very important to provide desulphurisation policy to combat sulphur emissions.

GHG and hazardous pollutant emissions

Figure 4a, b demonstrates GHG $\left(\mathrm{CO}_{2}\right)$ and hazardous pollutant $(\mathrm{Hg})$ stack emissions along with electricity 

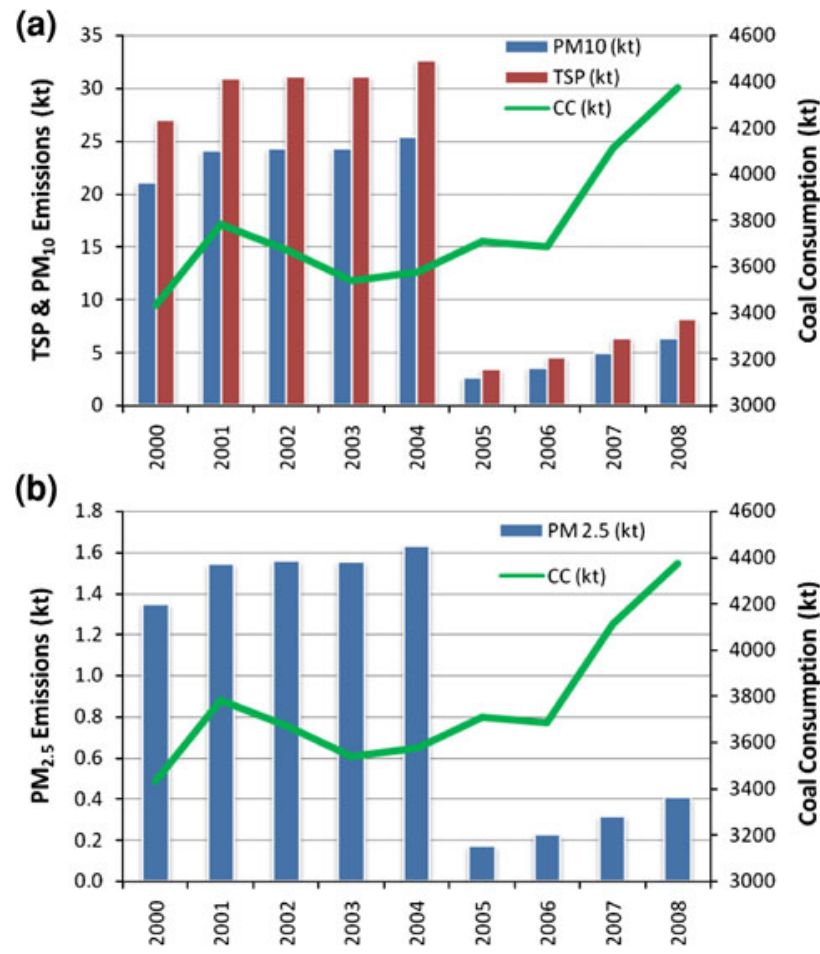

Fig. 2 Estimated Emissions of Particulates and coal consumption in BTPS, New Delhi during 2000-2008 a TSP, $\mathrm{PM}_{10}$ b $\mathrm{PM}_{2.5}$

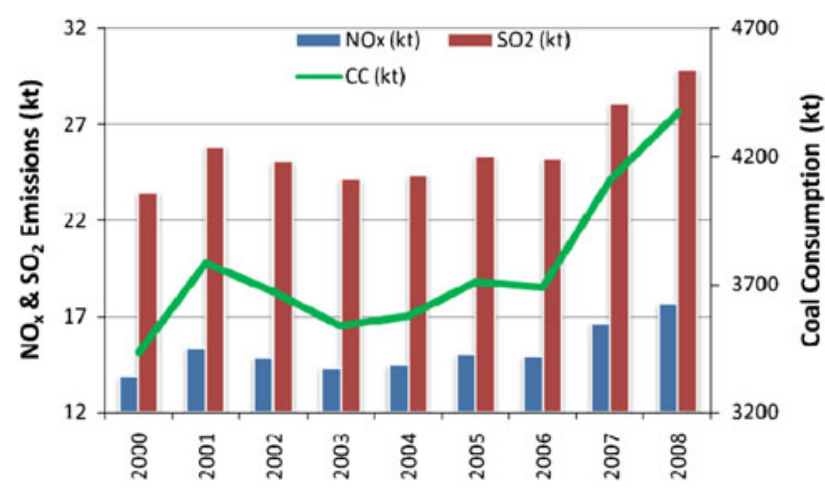

Fig. 3 Estimated gaseous pollutants emissions $\left(\mathrm{SO}_{2}, \mathrm{NO}_{\mathrm{x}}\right)$ and coal consumption in BTPS, New Delhi during 2000-2008

production and coal consumption from BTPS, New Delhi, from 2000 to 2008, respectively. The emission trend of $\mathrm{CO}_{2}$ emissions was similar to electricity production of the plant, whereas $\mathrm{Hg}$ emission trend can be seen similar to that of gaseous pollutants following the trend of coal consumption. The reduction in GHG stack emissions was noticed in 2002 and 2006 relative to lowered electricity production in the plant, whereas $\mathrm{Hg}$ emissions decreased from 2001 to 2006. Thereafter, $\mathrm{Hg}$ emissions increased relative to coal consumption up to 2008. The overall increase in GHG stack emissions was from 4,600 kt in 2,000-5,000 kt in 2008. It is also noticed that $\mathrm{Hg}$ stack
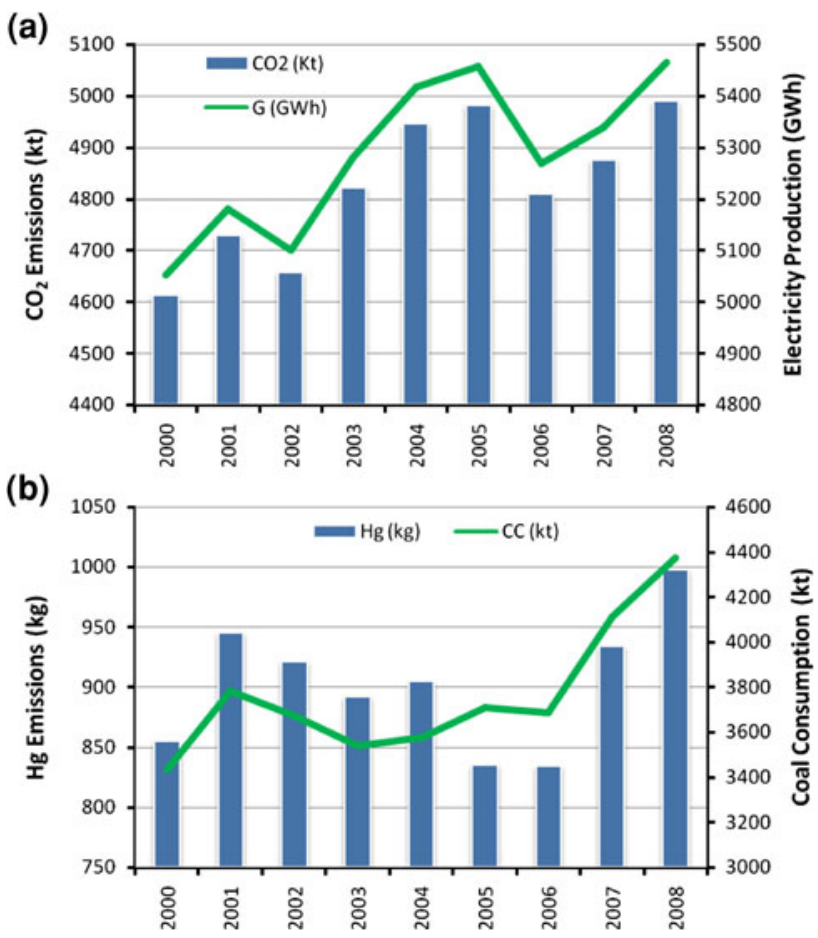

Fig. 4 Estimated GHG and Hazardous Pollutant Emissions from BTPS, New Delhi during 2000-2008 a CO 2 and electricity production b $\mathrm{Hg}$ and coal consumption

emissions were increased by $25 \%$ during 2006-2008 even after up-gradation of ESP. A new effective control policy, therefore, should be planned to control hazardous mercury emissions and to avoid significant health impacts incurred therein.

With the application of correction factors discussed in "Materials and methods", the CPSE model revealed plantand year-specific emission factors for BTPS, New Delhi, depending upon the plant characteristics as shown in Table 4.

Model evaluation/validation

The stack monitoring results are generally used to compare the emission performance of the plant with the current standards while the plant conditions are optimal (Vijay et al., 2004). Also, Lack of randomness in measurements and low measurement frequency gives rise to unfair annual stack emission estimations. Therefore, CPSE model has been validated by comparing trends of percentage change in annual emission estimations from the model with the observed ambient air concentrations of particulate matter (TSP and $\mathrm{PM}_{10}$ ) and $\mathrm{SO}_{2}$ during 2000-2008 at nearby air quality monitoring stations. There are two air quality monitoring stations nearby BTPS; Siri Fort and Nizamuddin. The air quality monitoring station at Siri Fort is comparatively nearer than that of Nizamuddin from BTPS, 
Table 4 Emission factors revealed for BTPS New Delhi by CPSE model

\begin{tabular}{llllll}
\hline Year & \multicolumn{5}{l}{ Emission factor for } \\
\cline { 2 - 6 } & $\mathrm{NO}_{\mathrm{x}}(\mathrm{g} / \mathrm{KWh})$ & $\mathrm{SO}_{2}(\mathrm{~g} / \mathrm{KWh})$ & $\mathrm{TSP}(\mathrm{g} / \mathrm{KWh})$ & $\mathrm{CO}_{2}(\mathrm{~g} / \mathrm{kg})$ & $\mathrm{Hg}(\mathrm{g} / \mathrm{t})$ \\
\hline 2000 & 2.75 & 4.64 & 5.34 & 1.34 & 0.249 \\
2001 & 2.96 & 4.98 & 5.96 & 1.25 & 0.250 \\
2002 & 2.92 & 4.91 & 6.10 & 1.27 & 0.251 \\
2003 & 2.71 & 4.57 & 5.89 & 1.36 & 0.252 \\
2004 & 2.67 & 4.50 & 6.01 & 1.38 & 0.253 \\
2005 & 2.75 & 4.64 & 0.62 & 1.34 & 0.225 \\
2006 & 2.84 & 4.78 & 0.86 & 1.30 & 0.226 \\
2007 & 3.12 & 5.26 & 1.19 & 1.19 & 0.227 \\
2008 & 3.24 & 5.46 & 1.49 & 1.14 & 0.228 \\
\hline
\end{tabular}

New Delhi. The observed concentrations of TSP, $\mathrm{PM}_{10}$ and $\mathrm{SO}_{2}$ at these two monitoring stations during 2000-2008 are adapted from online environmental data bank provided on website of Central Pollution Control Board (CPCB), New Delhi.

\section{Total suspended particles (TSP)}

Figure 5a, $\mathrm{b}$ illustrate the comparison of percentage change in annual TSP emissions and observed TSP concentrations at air quality monitoring stations namely Siri Fort and Nizamuddin.

Figure $5 \mathrm{a}, \mathrm{b}$ illustrate that the trends of percentage rise and drop in annual emissions and observed concentrations of TSP are matching for all 8 years at Siri Fort while in 5 years at Nizamuddin monitoring station. The matching trends make it clear that ambient TSP concentrations are significantly influenced by emissions from BTPS, New Delhi. As Siri fort is the nearest monitoring station from BTPS than Nizamuddin, BTPS seems to significantly contribute and influence TSP concentrations at Siri Fort than Nizamuddin.

\section{Respirable suspended particulate matter $\left(P M_{10}\right)$}

Figure $6 \mathrm{a}, \mathrm{b}$ show the comparison of percentage change in annual $\mathrm{PM}_{10}$ emissions and observed $\mathrm{PM}_{10}$ concentrations at air quality monitoring stations namely Siri Fort and Nizamuddin.

This is observed that for $\mathrm{PM}_{10}$ the trends of percentage increase and decrease in annual emissions and observed concentrations are matching during almost all years except 2000-01 at relatively near monitoring station of Siri Fort, whereas the trends are similar for 6 years at Nizamuddin. This difference could be because of the differences in location of two air quality monitoring stations. The monitoring station at Nizamuddin is comparatively at a farther


Fig. 5 Comparison of percentage change in annual TSP emissions and observed TSP concentrations at monitoring stations namely a Siri Fort b Nizamuddin

distance from BTPS and also local transport activities are the major source of $\mathrm{PM}_{10}$ concentrations (Nagpure, 2011).

\section{Sulphur dioxide $\left(\mathrm{SO}_{2}\right)$}

Figure $7 \mathrm{a}, \mathrm{b}$ illustrate the comparison of percentage change in annual $\mathrm{SO}_{2}$ emissions and observed $\mathrm{SO}_{2}$ concentrations at air quality monitoring stations namely Siri Fort and Nizamuddin. 

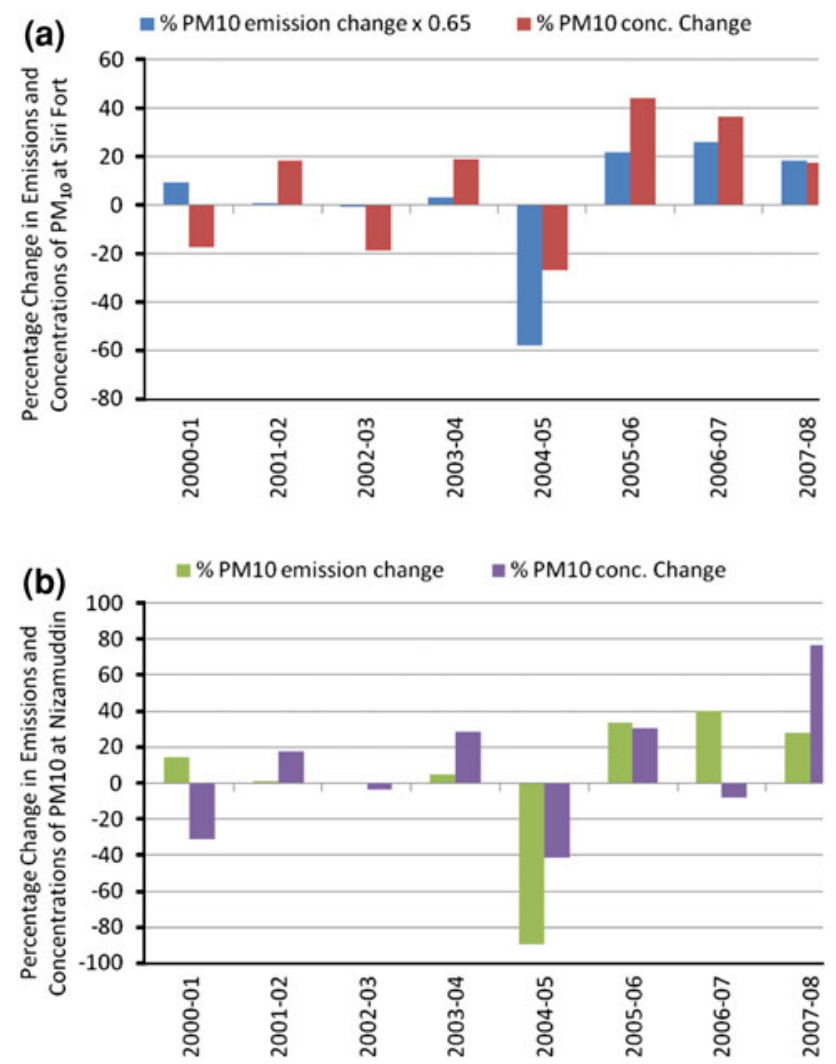

Fig. 6 Comparison of percentage change in annual $\mathrm{PM}_{10}$ emissions and observed $\mathrm{PM}_{10}$ concentrations at monitoring stations namely a Siri Fort b Nizamuddin

The trends of percentage change in annual emission estimates and observed concentrations of $\mathrm{SO}_{2}$ are matching during 5 years (2001-2002, 2002-2003, 2004-2005, 2005-2006 and 2007-2008) at air quality monitoring station of Siri Fort whereas for 4 years (2001-2002, 2002-2003, 2004-2005 and 2007-2008) at Nizamuddin. It is quite obvious that nearby sources at both monitoring stations (especially transportation activities on ring road and Mathura road adjoining to Siri Fort station) can influence $\mathrm{SO}_{2}$ concentrations proportionally. Diesel sulphur reduction program was implemented in 2000-2001 for all private and diesel vehicles in National Capital Territory (NCT) (CPCB, 2010). This resulted in dramatic decrease in ambient $\mathrm{SO}_{2}$ concentrations during 2000-2001. The high volume of commercial vehicles from Faridabad enters into Delhi through Mathura road (DUDGD 2006) which is very near to Siri Fort air quality monitoring station. According to CPCB (2010), Haryana State government issued a notification in December 2003 according to that the age for the operation of various types of transport vehicles in Faridabad had been fixed. Accordingly, phasing out of age old commercial vehicles in Faridabad could lead in lowering $\mathrm{SO}_{2}$ emissions during 2003-2004 at Siri Fort
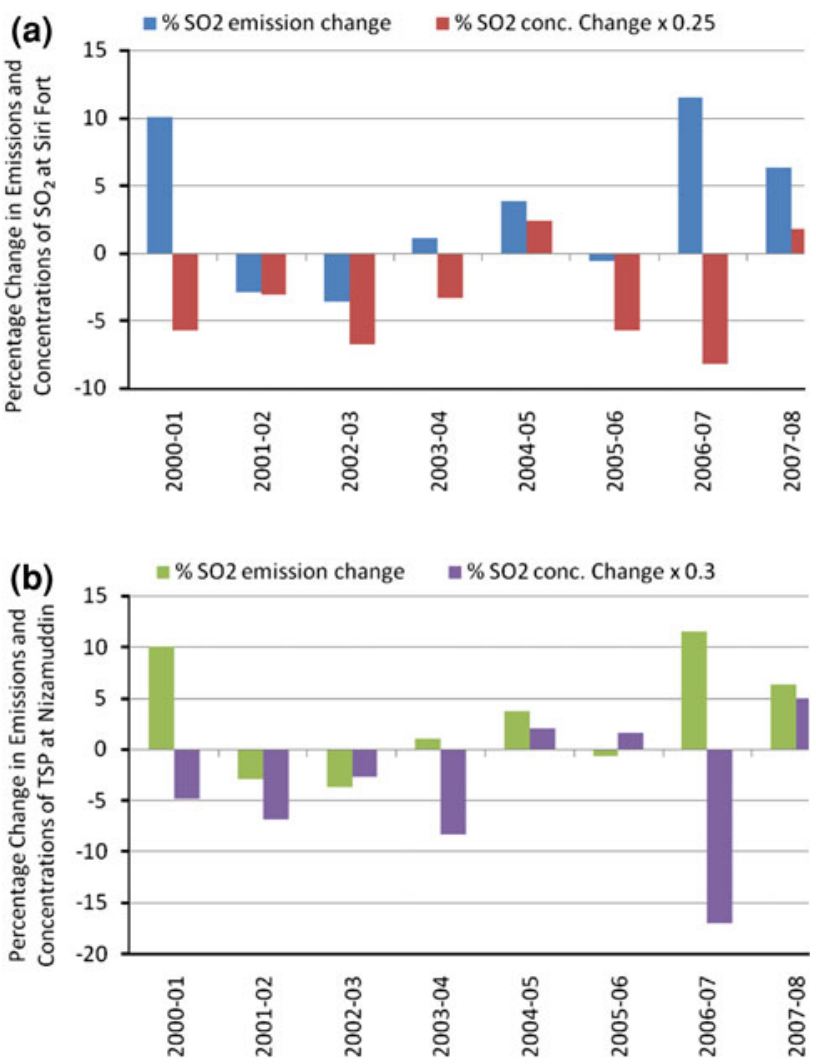

Fig. 7 Comparison of percentage change in annual $\mathrm{SO}_{2}$ emissions and observed $\mathrm{SO}_{2}$ concentrations at monitoring stations namely a Siri Fort b Nizamuddin

station. Delhi Government had also implemented mandatory Compressed Natural Gas (CNG) norms for light commercial vehicles (LCVs) in 2006 resulting into higher increase in CNG driven LCV population in 2007 to help reduce ambient $\mathrm{SO}_{2}$ concentrations during 2006-2007. Thus, contribution of vehicular emissions of $\mathrm{SO}_{2}$ could be a factor that might also influence the air quality concentration of $\mathrm{SO}_{2}$ proportionally at monitoring stations.

The above-mentioned and discussed matching trends in stack emission estimations and ambient air quality concentrations of TSP, $\mathrm{PM}_{10}$ and $\mathrm{SO}_{2}$ indicate that the proposed CPSE model works satisfactorily.

\section{Conclusion}

In the present study we have made an attempt to propose first ever plant-specific multi-year, multi-parameter stack emission model; namely Coal Power Stack Emission (CPSE) model, for Indian conditions. The CPSE model has been developed using MS Excel and Visual Basic Application (VBA). This model can be used to explore current and historical annual stack emissions from a coal based 
power plant taking into account essential variables. The CPSE model is applied to get historical and present emission trends from Badarpur Thermal Power Station (BTPS), New Delhi considering the essential variables like coal characteristics, process attributes, and control equipment features. The model results are successfully evaluated/ validated by comparing the trends of percentage change in annual TSP, $\mathrm{PM}_{10}$ and $\mathrm{SO}_{2}$ emissions and observed concentrations at nearby air quality monitoring stations namely Siri Fort and Nizamuddin. Study results indicate that the stack emission estimations from CPSE model reflect effects of different policy changes and technological interventions introduced in plant from time to time. Thus, we feel the proposed model can effectively be used to estimate stack emissions from coal based thermal power stations particularly in Indian conditions. We hope this will bridge the gap that presently exists in India in the area of stack emission estimation modelling for any coal based power plant. The results of stack emission estimations from CPSE model can further be useful for air quality assessment studies.

Acknowledgments First author sincerely acknowledge and thank the Ministry of Human Resource Development, Govt. of India, for supporting his $\mathrm{PhD}$ research work, which is the basis of this paper. Authors are grateful to the anonymous reviewers whose constructive suggestions have helped greatly improve the manuscript.

\section{References}

Asian Development Bank (ADB), 2009. Environmental assessment report, Summary environmental impact assessment, Project Number: 42933, India: Jhajjar Thermal Power Project, Prepared by Jhajjar Power Limited for the Asian Development Bank (ADB). http://www.adb.org/Documents/Environment/IND/42933/ 42933-IND-SEIA.pdf

Awasthi S, Khare M, Gargava P (2006) General plume dispersion model (GPDM) for point source emission. Environ Model Assess 11:267-276

Beer JM (2007) High efficiency electric power generation: the environmental role. Prog Energy Combust Sci 33:107-134

CPCB (Central Pollution Control Board), 2010. Status of the vehicular pollution control programme in India. Programme Objective Series, PROBES/136/2010 (Ministry of Environment \& Forests, Govt. of India), Delhi

CBIP (Central Board of Irrigation and Power), 1997. Compendium of thermal power stations in India, Vols I and II. Central Board of Irrigation and Power, New Delhi

Chakraborty N, Mukherjee I, Santra AK, Chowdhury S, Chakraborty S, Bhattacharya S, Mitra AP, Sharma C (2008) Measurement of $\mathrm{CO}_{2}, \mathrm{CO}$., $\mathrm{SO}_{2}$, and $\mathrm{NO}$ emissions from coal-based thermal power plants in India. Atmos Environ 42:1073-1082

Chikkatur, A.P., Sagar, A.D., 2007. Towards better technology policies for the Indian coal-power sector. Energy Sustainable Dev. Vol XI, No. 4

DUDGD (Department of Urban Development Government of Delhi), 2006. City Development Plan Delhi, Chapter-11. Review of Road Network and Transport System. http://www.ccsindia.org/
ccsindia/pdf/Ch11_Review\%20of\%20Road\%20Network\%20and \%20Transport\%20System.pdf

Garg A, Shukla PR, Kapshe M (2006) The sectoral trends of multigas emissions inventory of India. Atmos Environ 40:4608-4620

Ghosh S (2010) Status of thermal power generation in IndiaPerspectives on capacity, generation and carbon dioxide emissions. Energy Policy 38(11):6886-6899

Ghosh, M.K., 2011. Environmental issues in power generation and clean technologies. In training programme on environmental issues in thermal power plants. Pollution Control Research Institute (PCRI), Bharat Heavy Electricals Limited, Ranipur, Haridwar-249403, India

Gurjar BR, van Aardenne JA, Lelieveld J, Mohan M (2004) Emission estimates and trends (1990-2000) for megacity Delhi and implications. Atmos Environ 38(33):5663-5681

Kho WLF, Sentian J, Radojevi M, Tan CL, Law PL, Halipah S (2007) Computer simulated versus observed $\mathrm{NO}_{2}$ and $\mathrm{SO}_{2}$ emitted from elevated point source complex. Int $\mathrm{J}$ Environ Sci Technol 4(2):215-222

Miller, C.E., Feeley, T.J., Aljoe, W.W., Lani, B.W., Schroeder, K.T., Kairies, C., McNemar, A.T., Jones, A.P., Murphy, J.T. 2006. Mercury capture and fate using wet fgd at coal-fired power plants. Department of Energy, National Energy Technology Laboratory, Mercury and Wet FGD R\&D. http://www.netl.doe. gov/energy-nalyses/refshelf/PubDetails.aspx?Action=View\& PubId=242. Accessed 01 Jan 2012

Mittal, M.L, Sharma, C., 2004. Anthropogenic emissions from energy activities in India: generation and source characterization (Part I: emissions from thermal power generation in India). http://www. osc.edu/research/pcrm/emissions/India.pdf. Accessed 13 Dec 2011

MoP (Ministry of Power), 2011. Annual Report, 2010-2011, Ministry of Power, Government of India, New Delhi

Nagpure, A.S., 2011. Modeling of Urban Traffic Emissions, PhD Thesis. Centre for Transportation Systems (CTRANS) and Department of Paper Technology, Indian Institute of Technology Roorkee, India

Raghuvanshi SP, Chandra A, Raghav AK (2006) Carbon dioxide emissions from coal based power generation in India. Energy Convers Manage 47:427-441

Reddy MS, Venkataraman C (2002) Inventory of aerosol and sulphur dioxide emissions from India: i-Fossil fuel combustion. Atmos Environ 36:677-697

Rezvani S, Huang Y, McIlveen-Wright D, Hewitt N, Wang Y (2007) Comparative assessment of sub-critical versus advanced supercritical oxyfuel fired $\mathrm{PF}$ boilers with $\mathrm{CO}_{2}$ sequestration facilities. Fuel 86:2134-2143

Sengupta I (2007) Regulation of suspended particulate matter (SPM) in Indian coal-based thermal power plants: a static approach. Energy Economics 29:479-502

Shrestha RM, Timilsina GR (1997) $\mathrm{SO}_{2}$ emission intensities of the power sector in Asia: effects of generation-mix and fuelintensity changes. Energy Economics 19:355-362

Soltanali S, Shams Hagani Z, Pazouki Yaftabadi M (2008) Economic evaluation for air pollution control technologies selection in power plants processes. Int J Environ Sci Technol 5(4):555-564

TERI (The Energy and Resources Institute), 2011. TERI Energy Data Directory and Yearbook, 2010. TERI Press, New Delhi

Tian HZ, Wang Y, Xue ZG, Cheng K, Qu YP, Chai FH, Hao JM (2010) Trend and characteristics of atmospheric emissions of $\mathrm{Hg}$, As, and Se from coal combustion in China, 1980-2007. Atmos Chem Phys 10:11905-11919

Vijay, S., Molina, L.T., Molina, M.J., 2004. Estimating air pollution emissions from fossil fuel use in the electricity sector in Mexico. Integrated program on urban, regional and global air pollution, Prepared for North American commission for environmental 
cooperation, April 2004, Massachusetts Institute of technology, Cambridge

Wang, W., Jiang, Y., Yang, D., Wang, Q., Zhu, X., Wang, Z., 2001. The impact of ESP efficiency and counter measures when low sulphur coal begin to be used in coal-fired boilers. Presented at the 8th International Conference on Electrostatic Precipitation.
www.isesp.org/ICESP\%20VIII\%20PAPERS/VIII-ICESP\%20 PC4-3.pdfAccessed 15 Jan 2012

Zhao Y, Wang S, Duan L, Lei Y, Cao P, Hao J (2008) Primary air pollutant emissions of coal-fired power plants in China: current status and future prediction. Atmos Environ 42:8442-8452 